\title{
Ridge to Reef Management Implications for the Development of an Open-Source Dissolved Inorganic Nitrogen Loading Model in American Samoa
}

Christopher Shuler $^{1^{*}}$ and Mia Comeros-Raynal ${ }^{2}$

${ }^{1}$ Water Resources Research Center and Department of Earth Sciences, University of Hawaii at Manoa, 1680 East West Road, Honolulu, HI 96822, USA,

*Corresponding author: cshuler@ hawaii.edu, 1 (808) 9567847

${ }^{2}$ ARC Centre of Excellence for Coral Reef Studies, James Cook University, Townsville, Australia 4810

Comeros-Raynal ORCID iD: https://orcid.org/0000-0002-5087-8984

Shuler ORCID iD: https://orcid.org/0000-0001-5259-6684

Conflict of Interest: The authors declare that they have no conflict of interest. 


\begin{abstract}
Excessive nutrient discharge to tropical island coastlines drives eutrophication and algal blooms with significant implications for reef ecosystem condition and provision of ecosystem services. Management actions to address nutrient pollution in coastal ecosystems include setting water quality standards for discharging surface waters. However, these standards do not account for the effects of groundwater discharge, variability in flow, or dilution, all of which may influence assessment of true nutrient impacts on nearshore reef habitats. We developed a method to estimate dissolved inorganic nitrogen (DIN) loads to coastal zones by integrating commonly available datasets within a geospatial modeling framework for Tutuila, American Samoa. The DIN loading model integrated an open-source water budget model, water sampling results, and publically available streamflow data to predict watershed-scale DIN loading to the island's entire coastline. When compared to surface water pathways, submarine groundwater discharge (SGD) was determined to be the most important coastal delivery mechanism of terrigenous DIN, which supports findings from other tropical islands. Onsite wastewater disposal systems were also found to be the primary anthropogenic sources DIN to coastal waters. Our island-wide DIN loading model provides a simple and robust metric to define spatially-explicit sources and delivery mechanisms of nutrient pollution to nearshore reef habitats. Understanding the sources and primary transport modes of inorganic nitrogen to nearshore reef ecosystems can have significant implications for place-based management interventions aimed at increasing the adaptive capacity of unique island ecosystems to environmental variation and disturbances.
\end{abstract}

\title{
Keywords:
}

Nutrient Loading, Geospatial Model, Dissolved Inorganic Nitrogen, Water Quality, Island Management 


\section{Introduction}

On tropical islands, excessive nutrient discharge to naturally oligotrophic coastal waters can significantly disrupt the nearshore nutrient balance, potentially causing algal blooms or eutrophication (McCook 1999; Morton et al. 2011). In these environments, excessive nitrogen (N) loading, and in particular, high dissolved inorganic nitrogen (DIN) concentrations significantly affect phytoplankton, turf algae and macroalgae growth (e.g. Smith et al. 1981; Pendleton 1995). Nutrient enrichment can potentially lead to a transition from a coral-dominated state to an algal-dominated state on reefs (Hughes et al. 2007a; Littler et al. 2006; McCook 1999), with significant impacts to coral reef functions and ecosystem services (Hughes et al. 2007b).

Human population and development are dominant drivers of increased coastal nitrate and DIN concentrations (e.g. Caraco and Cole 1999; Waterhouse et al. 2017), Because coastal water DIN concentrations have been shown to be reliable predictors of nearshore reef ecological condition (Comeros-Raynal et al. 2019; Delevaux et al. 2018), management actions often include water quality monitoring and defining nutrient-based water quality standards for surface water discharge and coastal surface waters (AS-EPA 2013; Hawai'i Administrative Rules 2013; SWRCB 2015). Water quality standards typically focus on sampling streams and rivers to assess terrigenous inputs, which considers only the surface water pathways of nutrient transport. However, this paradigm does not account for the important effects of diffuse or point source groundwater seepage otherwise known as submarine groundwater discharge (SGD). In tropical island settings across the globe, SGD has been shown to deliver an equivalent or significantly higher nutrient load to coastal ecosystems than streamflow (e.g. D'elia et al. 1981; Moosdorf, et 
al. 2015; Bishop et al. 2017; Shuler et al. 2019). In addition, water quality standards are often set using only nutrient concentrations, which may not be representative of the true impact of freshwater discharge, due to the effects of in-stream or coastal water dilution. However, nutrient loads account for variability in flow and can more accurately reflect water quality conditions providing better predictions of the impacts from terrestrial discharge on nearshore reef ecosystems. Nutrient loads are generally calculated by multiplying concentrations of nutrients or other constituents by volumetric rates of water discharge (e.g. Delevaux et al. 2018). Although other factors such as wind, nearshore circulation, and wave driven currents affect the fate of dissolved nutrients upon reaching the ocean, assessment of terrestrial loading affords a better understanding of how land use affects the coastal zone and also provides a comparative dataset for contextualizing biological field results or parameterizing environmental models.

In this study, we integrated commonly available datasets within a geospatial modeling framework designed to estimate island-wide DIN loading rates at a watershed scale. We developed a DIN loading model for Tutuila, American Samoa by combining output from an existing Tutuila-based open-source water budget model, existing water sample data for one year from nearly a third of the island's numerous watersheds, and publically available streamflow data. We then identified locations or land use activities likely to be the highest nutrientmanagement priorities on Tutuila. This was accomplished by summarizing model results through a unique watershed impact ranking score to help coastal and terrestrial land managers assess which of the island's watersheds are subject to the greatest anthropogenic impacts, based on DIN loads. We examined the relative importance of different hydrologic pathways (e.g., baseflow, surface runoff, and SGD) as nutrient transport mechanisms, and the impacts of loading from 
individual land use DIN sources including wastewater, piggeries, and agriculture were also assessed. Finally, we directly related the results of the nutrient loading model to a management decision making framework through stakeholder engagement and by producing innovative and open-source model outputs, thereby improving accessibility, reproducibility, and transparency to benefit stakeholders and others who may wish to apply this method in different locales.

\section{Methods and Model Inputs}

\section{Study location}

The island of Tutuila is the largest and most populous island in the Territory of American Samoa (Fig 1). Tutuila is located in the South Pacific Ocean near the coordinates of $14^{\circ} 20^{\prime} \mathrm{S}$ and $170^{\circ}$ 40 ' W, with a land area of $142 \mathrm{~km}^{2}$, and a population of 56,000 (AS-DOC 2013). Tutuila's climate is warm and humid, and due to its position within the South Pacific Convergence Zone, the island receives significant rainfall, between 1,800 to $5,000 \mathrm{~mm} / \mathrm{yr}$. depending on location and elevation (Daly et al. 2006). The majority of Tutuila's human development is located on the Tafuna-Leone Plain, with development off the plain concentrated on narrow strips of coastal land and in steep sided valleys. The three primary anthropogenic land use types (i.e. nutrient sources) previously identified on Tutuila include: On-Site wastewater Disposal Systems (OSDS), smallscale pig farms, and agricultural fertilizers (Shuler et al. 2017).

Fig 1 Study location map of Tutuila Island showing location of the Samoan Archipelago, and hill-shaded topography of Tutuila 


\section{Modeling Framework}

The Tutuila DIN loading model accounted for three hydrologic pathways from land to sea including (1) stream baseflow from shallow aquifers, (2) surface runoff generated during rainfall events, and (3) submarine groundwater discharge (SGD) across the ocean-land interface into the coastal zone. The anthropogenic DIN sources accounted for in the model were: on-site wastewater disposal systems (OSDS), livestock pigs, and synthetic fertilizer inputs to agricultural lands. The model followed a four-part workflow (Fig 2). First, we used an existing open-source Tutuila-based water budget model, calibrated with historical streamflow data, to calculate island-wide water discharge rates from all three hydrologic pathways. Secondly, we multiplied measured DIN concentrations in each hydrologic pathway by water discharge rates from the previous step to calculate observed DIN loads. For the third step, we used highresolution geospatial data to calculate the prevalence of anthropogenic and natural DIN sources in every watershed by identifying the total numbers of OSDS units, numbers of pigs in piggeries (small backyard-scale livestock rearing operations), and estimated synthetic fertilizer inputs to agricultural lands within each watershed. Finally, we calculated modeled DIN fluxes for all watersheds across the island by optimizing the coastal DIN loading model using measured fluxes as calibration data. Modeled DIN loading was calculated on the scale of individual watersheds, with watershed boundaries defined by using boundaries in an existing dataset (AS-DOC, 2002) and merging non-sampled sub-watersheds. This resulted in a total of ninety-three individual watersheds assessed by the model. 
Fig 2 Schematic of DIN loading model workflow. The SWB2 component represents the water budget model used to determine water discharge rates and observed streamflow and nutrient fluxes are from field data used to calibrate and validate the model. The DIN release rates were initially parameterized with values from Shuler et al. (2017) and final rates were determined through loading model calibration. Steps marked with Xs indicate multiplication of values used to calculate derived components

\section{Step 1. Island-wide water discharge rates from all three hydrologic pathways}

Annual resolution, island-wide water discharge rates to the coastal zone were estimated for all hydrologic pathways (i.e., stream baseflow, surface runoff and groundwater discharge) using an existing water budget model developed for Tutuila (Shuler and El-Kadi 2018). The water budget model used the Soil-Water Balance 2 (SWB2) code (Westenbroek et al. 2018). The SWB2 model - originally developed by the U.S. Geological Survey (USGS) - is based on the soil-water balance formulation originally developed by Thornthwaite-Mather (1955). The Shuler and ElKadi water budget model is publically accessible, published under an open access license, and is available for download by following the link in Shuler and El-Kadi (2019). The existing can be easily modified to develop estimates of discharge from any hydrologic pathway within user-set geographic boundaries. The input data to the Tutuila water budget model included precipitation data, land use data, soil type data, direct infiltration layers, runoff-to-rainfall ratios, potential evapotranspiration data, maximum and minimum temperature data and mountain front recharge information. The model output included island-wide estimates of water budget components including precipitation, evapotranspiration, runoff, streamflow infiltration, and groundwater recharge. Detailed information regarding sources of inputs and calculation of outputs is detailed in Shuler and El-Kadi (2018). 
Because SWB2 was not originally developed to model subsurface processes, it cannot determine the proportions of groundwater recharge that ultimately become baseflow or SGD. To explicitly partition baseflow and SGD, we developed an island-wide baseflow to net-infiltration ratio, using publically available continuous record streamflow measurements to calculate measured baseflow rates, which could then be subtracted from the SWB2 modeled groundwater recharge in measured basins to obtain SGD rates. This was done by calculating observed baseflow rates for continuously gauged watersheds (Online Resources Fig OR1 and Table OR1) through baseflow separation analysis of total streamflow (Wahl and Wahl 1995). We obtained total streamflow data from two sources, historical USGS data (Wong 1996; Perreault 2010;

https://waterdata.usgs.gov/nwis), and a streamflow measurement network maintained by the American Samoa Power Authority (ASPA) and the University of Hawaii (UH) (Shuler and Mariner 2019). We then subtracted the calculated baseflow plus the amount of water lost to pumping in each watershed (ASPA 2017) from SWB2 net-infiltration estimates, yielding the difference, which was interpreted to be the amount of SGD originating from each watershed. Net-infiltration to SGD and baseflow ratios in each watershed were then averaged, and we applied this average ratio to the SWB2 calculated groundwater recharge in ungauged watersheds to estimate island-wide SGD and baseflow rates, respectively. The weighted average baseflow to net-infiltration ratio (weights based on streamflow data period of record) from all gauged watersheds was $33 \% \pm 17 \%$, with the SGD fraction equaling 1 - the baseflow fraction. This method was used to calculate island-wide modeled SGD and baseflow rates for all of Tutuila's watersheds except for those located on the Tafuna-Leone Plain (Fig 1), where no perennial streams flow, and young and fractured lava flows promote rapid infiltration and high aquifer 
permeabilities (Bentley 1975; Izuka et al. 2007). Therefore, we classified 100\% of the SWB2 calculated net-infiltration as SGD in the plain area.

Uncertainties on water fluxes were determined in multiple ways. The above calculated $17 \%$ uncertainty represents the $1 \sigma$ standard deviation of the weighted average baseflow and SGD to net-infiltration ratios from all gauged watersheds. However, a set of independently-calculated, snapshot-resolution SGD measurements from four of Tutuila's bays taken by Shuler et al. (2019) suggested this uncertainty may be too low. While comparison between SGD rates as calculated by this study and from Shuler et al. (2019) suggest our SWB2 estimated SGD fluxes are reasonable (Online Resource Table OR2), the relative percent difference (RPD) between the two datasets was $48 \%$, which is significantly higher than the aforementioned $17 \%$ uncertainty. The Shuler et al. (2019) data is the only available information for validating these estimates, and comparison to the measured SGD rates is the most conservative way to determine the uncertainty on our SGD/baseflow partitioning. Therefore, we used $48 \%$ as the uncertainty on our SWB2 calculated SGD and baseflow rates. Uncertainty on SWB2 surface runoff rates could be directly calculated because SWB2 does directly calculate surface runoff fractions. Comparison between baseflow separated measured flows and the SWB2 calculated surface runoff totals (Online Resource Fig OR2) yielded a Mean Absolute Percentage Error (MAPE) of 21\%, which was used to represent the uncertainty on the SWB2 surface runoff values. 


\section{Step 2. Measured DIN fluxes}

\section{Water Sampling and Nutrient Concentrations}

We obtained existing water quality data from stream and coastal spring samples taken throughout Tutuila by Comeros-Raynal et al. (2019), Shuler et al. (2017, 2019), and Shuler (2019). Stream sampling data from Comeros-Raynal (2019) were collected from 38 individual stream sites for a one-year period from September 2016 to September 2017 (Fig 3), and consisted of a total of 424 individual stream samples. All of the Comeros-Raynal stream samples were collected at low tide and were taken at stream outlets to ensure samples were representative of the discharge directly affecting coastal waters. Additionally, at each stream sample site, a staff gauge was installed in order to document the relative water height (stage) during each sampling event. While it was not possible to derive streamflow rates with stream height alone, the stage measurements provided a rough approximation of the flow regime during each sampling event. To distinguish between baseflow and surface runoff flow regimes, we calculated the average stage for each site and used this as a threshold value to classify the sample as either a baseflow sample or a surface runoff sample. We considered any sample taken when the stream stage exceeded the mean to be surface runoff, and any sample taken when the stage was lower than the threshold was considered to be baseflow.

The Comeros-Raynal (2019) dataset also included coastal spring samples collected from 26 locations around Tutuila (Fig 3), with sampling conducted approximately every three months. We grouped additional coastal spring data collected at 31 locations from 2013 and 2018 (Shuler et al. 2017, 2019) with the Comeros-Raynal coastal spring data to supplement the groundwater end-member dataset (Fig 3) for a total of 81 coastal spring samples. All stream and coastal spring samples were analyzed for nitrate $\left(\mathrm{NO}_{3}^{-}\right)$, nitrite $\left(\mathrm{NO}_{2}^{-}\right)$and ammonium $\left(\mathrm{NH}_{4}{ }^{+}\right)$concentrations, 
which when summed, represent the DIN concentration. See Shuler (2019) and Comeros-Raynal et al. (2019) for more detailed sampling and nutrient analysis methodologies.

Fig 3 Locations of stream and coastal spring sample sites shown as circles and triangles, respectively, with shaded model watersheds draining to each site. Model designated watershed ID numbers are also shown for reference

\section{Observed DIN Loads}

We calculated observed watershed scale DIN loads by multiplying measured DIN concentrations with water discharge rates. These DIN loads were then used to calibrate the nutrient loading model. Because most water sampling sites were sampled repeatedly, DIN concentrations at each site were grouped by hydrologic pathway (surface runoff, baseflow, or SGD) and average DIN concentrations for each pathway at each site were individually calculated. To estimate the average individual DIN loading rates for each sampled pathway in every sampled watershed, we multiplied the average DIN concentrations by pathway-specific SWB2 modeled water fluxes for each watershed. Of the ninety-three watersheds delineated for this project, thirty-four were sampled for surface water nutrients, and coastal springs were sampled in twenty-two. However, of these, only thirteen were sampled for both surface waters and coastal springs (Fig 3), partially due to the fact that hydrogeologic regions with more SGD (i.e. more prevalent coastal springs) often have fewer surface water features. Therefore, total observed coastal DIN fluxes (summed from all three pathways) could only be calculated in these thirteen watersheds. All observed watershed scale DIN fluxes for each hydrologic pathway are presented in Table 1. Uncertainties on total DIN loading were calculated by propagating error from the SWB2 fluxes (as described in step 1) and the $1 \sigma$ standard deviation of DIN concentrations in sample waters. 
Table 1: Watershed scale DIN loading rates calculated with observed nutrient concentrations (Comeros-Raynal et al. 2019) and SWB2 calculated water fluxes (Shuler and El-Kadi 2019). Values in parentheses represent propagated uncertainties. Watershed ID numbers reference those shown on Fig 3

\begin{tabular}{|c|c|c|c|c|}
\hline $\begin{array}{l}\text { Watershed ID \#, } \\
\text { Watershed Name }\end{array}$ & $\begin{array}{c}\text { Baseflow } \\
\text { DIN Load } \\
{[\mathrm{kg} / \mathrm{d}]}\end{array}$ & $\begin{array}{l}\text { Runoff DIN } \\
\text { Load [kg/d] }\end{array}$ & $\begin{array}{c}\text { SGD DIN } \\
\text { Load [kg/d] }\end{array}$ & $\begin{array}{c}\text { Total DIN } \\
\text { Load }[\mathrm{kg} / \mathrm{d}]\end{array}$ \\
\hline$\# 0$, Leone & $0.21(0.13)$ & $0.21(0.19)$ & $1.71(1.05)$ & $2.13(1.08)$ \\
\hline \#1, Amanave & $0.03(0.02)$ & $0.11(0.08)$ & - & - \\
\hline$\# 2$, Nua - Seetaga & - & - & $0.19(0.19)$ & - \\
\hline \#4, Amanave & $0.06(0.04)$ & $0.14(0.12)$ & $0.27(0.20)$ & $0.48(0.24)$ \\
\hline \#5, Afao - Asili & $0.30(0.17)$ & $0.30(0.11)$ & - & - \\
\hline \#9, Fagaalu & $0.92(0.72)$ & $0.43(0.39)$ & $3.62(2.39)$ & $4.97(2.53)$ \\
\hline \#13, Fagamalo & $0.10(0.07)$ & $0.30(0.11)$ & - & - \\
\hline \#17, Malaeloa & $1.69(1.29)$ & $2.02(1.15)$ & - & - \\
\hline \#18, Maloata & $0.50(0.51)$ & $0.87(0.45)$ & - & - \\
\hline \#21, Matuu -Faganeanea & $0.28(0.23)$ & $0.22(0.10)$ & - & - \\
\hline \#24, Nua - Seetaga & $0.17(0.09)$ & $0.56(0.79)$ & $0.94(0.52)$ & $1.67(0.95)$ \\
\hline \#25, Nuuuli Pala & $0.14(0.10)$ & $0.22(0.04)$ & - & - \\
\hline \#31, Nuuuli Pala & - & - & $7.15(3.87)$ & - \\
\hline \#33, Poloa & $0.17(0.15)$ & $0.26(0.12)$ & $0.37(0.25)$ & $0.80(0.32)$ \\
\hline \#35, Alega & $0.37(0.24)$ & $0.37(0.24)$ & $1.01(0.95)$ & $1.76(1.01)$ \\
\hline \#40, Fagaitua & $0.16(0.09)$ & $0.12(0.06)$ & - & - \\
\hline \#41, Fagaitua & $0.13(0.11)$ & $0.06(0.05)$ & - & - \\
\hline \#43, Fagaitua & $0.07(0.05)$ & $0.02(0.00)$ & - & - \\
\hline \#46, Amouli & $0.22(0.34)$ & $0.04(0.02)$ & $0.35(0.2)$ & $0.61(0.40)$ \\
\hline \#51, Amouli & $0.06(0.05)$ & $0.04(0.01)$ & - & - \\
\hline \#58, Aoa & $0.30(0.21)$ & $0.18(0.12)$ & $0.74(0.57)$ & $1.22(0.62)$ \\
\hline \#60, Aoa & $0.25(0.23)$ & $0.16(0.04)$ & - & - \\
\hline \#61, Fagaitua & $0.23(0.28)$ & $0.04(0.01)$ & - & - \\
\hline \#62, Fagaitua & - & - & $0.82(0.43)$ & - \\
\hline \#63, Fagaitua & $0.06(0.05)$ & $0.06(0.05)$ & - & - \\
\hline \#65, Fagatele - Larsen & - & - & $18.96(18.9)$ & \\
\hline \#66, Fagatele - Larsen & $0.08(0.05)$ & - & $0.08(0.08)$ & - \\
\hline \#67, Laulii - Aumi & $0.37(0.27)$ & $0.38(0.14)$ & $4.48(3.22)$ & $5.22(3.24)$ \\
\hline \#70, Masausi & $0.04(0.02)$ & $0.03(0.01)$ & - & - \\
\hline \#73, Masausi & $0.04(0.03)$ & $0.05(0.02)$ & - & - \\
\hline \#74, Masefau & $0.70(0.47)$ & $0.53(0.48)$ & - & - \\
\hline$\# 75$, Afono & $0.60(0.50)$ & $1.13(0.80)$ & $2.98(1.22)$ & $4.71(1.54)$ \\
\hline$\# 76$, Vatia & $0.15(0.09)$ & $0.17(0.07)$ & - & - \\
\hline \#77, Pago Pago Harbor & $1.28(1.11)$ & $2.77(2.29)$ & $4.19(2.53)$ & $8.25(3.59)$ \\
\hline \#82, Fagasa & $0.34(0.24)$ & $0.53(0.18)$ & - & - \\
\hline \#85, Fagasa & $1.00(0.80)$ & $0.72(0.30)$ & - & - \\
\hline \#89, Afono & $0.09(0.07)$ & - & $0.36(0.15)$ & \\
\hline$\# 90$, Vatia & $0.19(0.16)$ & $0.28(0.10)$ & $0.71(0.43)$ & $1.17(0.47)$ \\
\hline \#91, Vatia & $0.74(0.66)$ & $1.21(1.51)$ & $2.08(1.35)$ & $4.03(2.13)$ \\
\hline \#92, Vatia & $0.09(0.06)$ & $0.12(0.05)$ & - & - \\
\hline \#98, Leone & - & - & 31.78 (15.97) & - \\
\hline
\end{tabular}




\section{Step 3. Identification of Terrestrial DIN Sources}

We considered four terrestrial DIN sources as drivers for the model: three anthropogenic sources (OSDS, piggeries, and agricultural fertilizer input), and DIN from natural sources such as leaf litter and animal waste (Shuler et al. 2017). To resolve the spatial distribution of anthropogenic DIN sources to the watershed scale, we obtained the locations of every OSDS unit, every pig, and all known agricultural land on the island and geospatially intersected these anthropogenic DIN sources with watershed boundaries (Fig 4). The OSDS units were located using the methods of Shuler et al. (2017), by identifying all buildings located more than $50 \mathrm{~m}$ from a sewer main or service line and under $120 \mathrm{~m}^{2}$ in size. These buildings were assumed to rely on an OSDS unit for wastewater disposal. Small buildings were excluded since sheds or outbuildings typically do not contain facilities requiring an OSDS unit. Building locations were obtained from the American Samoa Department of Commerce (AS-DOC 2009) and sewer line locations were obtained directly from ASPA. Locations of piggeries and the number of pigs in each was obtained directly from the American Samoa Environmental Protection Agency (AS-EPA). While there exists no direct data regarding fertilizer application in American Samoa, we considered agricultural areas from the Meyer et al. (2016) land use map to be the most likely locations for fertilizer applications. To initialize the model calibration, we used DIN release rates from Shuler et al. (2017) for the equivalent source-activities on Tutuila. 
Fig 4 Locations of DIN sources used as model input. Initial DIN release rates from Shuler et al. (2017) were $0.021 \mathrm{~kg}$-DIN/day per OSDS unit, $0.0381 \mathrm{~kg}-\mathrm{DIN} /$ day per pig, $0.77 \mathrm{~kg}$ $\mathrm{DIN} /$ day per $\mathrm{km} 2$ of agricultural land, and $0.36 \mathrm{~kg}-\mathrm{DIN} /$ day per $\mathrm{km} 2$ of natural land

\section{Step 4. Model Calibration Process}

We calibrated the DIN loading model by parameterizing an individual DIN release rate for each of the anthropogenic sources. Parameter optimization was performed using the Nelder-Mead unconstrained minimization method (Nelder and Mead 1965). The optimization was implemented in Python using the scipy.optimize.minimize function.

(https://docs.scipy.org/doc/scipy-0.14.0/reference/generated/scipy.optimize.minimize.html). The selected objective function was a linear regression between calculated and modeled nutrient loads, with the slope of the regression fixed at 1 , so the optimization would be forced to minimize error without biasing the model towards over or under prediction, which could occur with an unconstrained least-squares regression. When error was minimized by the optimization routine, the model's mean average error (MAE) was $\pm 1.08 \mathrm{~kg}$-DIN/day and the $\mathrm{r}^{2}$ of the regression was 0.74 (Fig 5). Comparing observed modeled DIN loads for the watersheds with observed total loads yielded an MAE of $\pm 1.08 \mathrm{~kg}$-DIN/day, which if divided by the modeled loading rate for the thirteen watersheds used for calibration yields an average percent error of $74 \%$. We note that this optimization step acts as a "black-box" to conceptually represent all attenuation and $\mathrm{N}$-transformation processes between sources and sinks, by using a single lumped parameter for each DIN release rate. In reality, these processes are complex, non-linear, interdependent, and spatially distributed, which makes it extremely difficult to accurately model them directly. 
Fig 5 Scatterplot of final calibrated observed vs. modeled total DIN loads, with error bars representing propagated error on observed loads. Although the non-linearity of model optimization precluded standard error propagation through the model, the mean average error (MAE) associated with model calibration was $1.08 \mathrm{~kg}-\mathrm{DIN} / \mathrm{d}$. Grey line is the 1:1 line and represents a fixed model slope of 1

\section{Management Decision-making Framework}

To maximize the potential for integration of this work into management decision making, we worked directly with representatives from government agencies including AS-EPA, the National Marine Sanctuaries, and the Coral Reef Advisory Group to prioritize desired outputs. We then implemented the modeling process using a combination of traditional and innovative approaches to make the results as readily accessible as possible. For example, the model workflow is documented as an interactive Jupyter Notebook (Kluyver et al. 2016) that contains results and explanations as well as fully executable code, which can be used to reproduce or modify the model output. We made all model input data, code, and results available to anyone including stakeholders or other researchers in an open-access repository (http://doi.org/10.5281/zenodo.3462869). These resources were specifically developed to be understandable and accessible to stakeholders through publication-quality annotation and inclusion of metadata. Developing the project within this paradigm provides for easy reproduction and update of the nutrient loading model as additional water sampling data, better constrained land use data, or other management considerations become available in the future. 


\section{Results}

\section{Modeled DIN Loads}

The optimization routine provided calibrated values for DIN release rates from each of the three modeled anthropogenic nutrient sources by minimizing error between observed and modeled watershed-scale DIN loading rates. Calibration resulted in final modeled DIN release rates of $0.037 \mathrm{~kg}$-DIN/day per OSDS unit, $0.010 \mathrm{~kg}$-DIN/day per pig, and $0.579 \mathrm{~kg}$-DIN/day per $\mathrm{km}^{2}$ of agricultural land. Multiplication of these release rates by the number of anthropogenic DIN sources in each watershed yielded absolute loading rates ranging from $0.1 \mathrm{~kg}$-DIN/day for some of the smallest watersheds, to $88.2 \mathrm{~kg}$-DIN/day for the largest watershed on the Tafuna-Leone Plain. For interpretation, DIN loading rates were also scaled by watershed area (Fig 6), and by length of watershed coastline (Fig 7). These approaches remove the watershed-size dependence of the absolute loads and may be more representative of the relative impact of DIN sources within each watershed on the terrestrial landscape or in the coastal zone.

Because we considered each of the modeled DIN sources separately, their relative impact on the total load could be separated and examined. The fraction of total DIN loading originating from each of the individual sources is shown graphically in Fig 8, where total modeled DIN loads from each watershed are shown in the upper left panel, and the other three panels (clockwise from upper right) show the proportion of DIN loaded to each watershed from OSDS units, pigs, and agriculture, respectively. When summed, island-wide, model-predicted DIN load from all sources equaled approximately $410 \mathrm{~kg}-\mathrm{DIN} / \mathrm{day}$. Of this, the model predicted about $260(63 \%)$ was from OSDS units, about 110 (27\%) from pigs, 35 (9\%) from natural sources, and only 6 $(1 \%) \mathrm{kg}$-DIN/day from agriculture. The average \%-uncertainty (Table 1) for observed loading 
rates in the thirteen watersheds with observed DIN fluxes from all pathways was $55 \%$. While uncertainties could not be directly propagated through the optimization routine, this uncertainty is the lowest possible uncertainty estimate for modeled loading rates. The upper range of possible uncertainties would include this $55 \%$ plus any uncertainty derived from optimization of each of the model parameters. Although this uncertainty cannot be directly constrained, the average percent error of the regression between observed and modeled DIN loads, totaling 74\%, provides an indication of how well the calibration performed, and thus gives another indication of the order of magnitude for uncertainties on modeled DIN loads. The effect of each model parameter on the overall results was also examined though sensitivity testing as described in the next section.

Fig 6 Relative model calculated DIN loading rates for each watershed scaled by sub watershed area, in $\mathrm{kg}$-DIN/day per $\mathrm{km}^{2}$ of land and Numbers within watersheds show each of the DIN loads in $\mathrm{kg} / \mathrm{day} / \mathrm{km}^{2}$

Fig 7 Relative model calculated DIN loading rates for each watershed, scaled by length of watershed shoreline in $\mathrm{kg}$-DIN/day per $\mathrm{km}$ of coastline. Numbers within watersheds show each of the DIN loads in $\mathrm{kg} / \mathrm{day} / \mathrm{km}$

Fig 8 Comparisons between modeled DIN loading rates as separated by each nutrient source. Upper left panel shows total modeled DIN loads from all sources, and the other three panels (clockwise from upper right) show the absolute magnitude of DIN loaded to each watershed from OSDS units, pigs, and agriculture, respectively

\section{Sensitivity Testing}

To examine the model's sensitivity to each of the anthropogenic DIN release rates, we calculated modeled island-wide DIN loading for a variety of 'scenarios' representing a \%-shift in individual 
release rates. Loading rates for OSDS, pigs, and agricultural sources were modified independently by $-50 \%,-25 \%,-10 \%,+10 \%,+25 \%$, and $+50 \%$, and a fourth set of scenarios was run where all three anthropogenic loadings were modified by the aforementioned \%-change values at the same time. Sensitivity test results were compared to the base case model by computing the \%-difference between the scenario and the base-case for island-wide DIN loading. Results indicated the model is most sensitive to OSDS loading rates and least sensitive to agricultural loading rates (Table 2).

Table 2: Sensitivity test results for assessment of DIN release rates. Rates from each of the individual anthropogenic sources were varied independently and together for a total of six different values of relative changes, ranging from $-50 \%$ to $+50 \%$.

\begin{tabular}{|c|c|c|c|c|c|c|c|}
\hline \multirow[b]{2}{*}{$\begin{array}{l}\text { Percent change in } \\
\text { modeled loading }\end{array}$} & \multicolumn{7}{|c|}{ Sensitivity Test Change in Modeled Input Loading Rates } \\
\hline & $-50 \%$ & $-25 \%$ & $-10 \%$ & $\mathbf{0 \%}$ & $+10 \%$ & $+25 \%$ & $+\mathbf{5 0 \%}$ \\
\hline & \multicolumn{7}{|c|}{$\begin{array}{l}\text { Resulting Change in Modeled Output Island-Wide DIN Loading } \\
\text { Rate }\end{array}$} \\
\hline $\begin{array}{c}\text { All parameters } \\
\text { changed }\end{array}$ & $54 \%$ & $77 \%$ & $91 \%$ & $100 \%$ & $109 \%$ & $123 \%$ & $146 \%$ \\
\hline $\begin{array}{c}\text { Only OSDS } \\
\text { loading changed }\end{array}$ & $69 \%$ & $84 \%$ & $94 \%$ & $100 \%$ & $106 \%$ & $116 \%$ & $131 \%$ \\
\hline $\begin{array}{l}\text { Only piggery } \\
\text { loading changed }\end{array}$ & $87 \%$ & $94 \%$ & $97 \%$ & $100 \%$ & $103 \%$ & $106 \%$ & $113 \%$ \\
\hline $\begin{array}{l}\text { Only Ag. loading } \\
\text { changed }\end{array}$ & $99 \%$ & $99 \%$ & $100 \%$ & $100 \%$ & $100 \%$ & $101 \%$ & $101 \%$ \\
\hline
\end{tabular}

\section{Exploration of Correlation Relationships}

Although the model could only be calibrated using the thirteen watersheds for which

measurements of both surface and groundwater were collected, we also produced two-variable linear regressions to explore how variability in modeled loading from individual DIN sources 
related to variability in observed loads for individual hydrologic pathways. Fig 9 provides a scatterplot matrix showing least-squares regressions between observed DIN and modeled DIN loads. Observed loads can be separated by hydrologic pathway, each of which were plotted in a dedicated column of the scatterplot matrix, and while modeled loads cannot be separated by pathway, they can be separated by different sources, each of which were plotted in a dedicated row of the matrix. Additive total observed and modeled loads for each DIN source and each hydrologic pathway were plotted on the rightmost column and the bottom row, respectively. Compared across rows, the slopes of regression relationships indicate the relative importance of each source to the total DIN load in each pathway. Regressions with higher slopes suggest that more of the DIN in the given pathway originates from the cross-plotted source. Similarly, when plots are compared across columns, those with higher $r^{2}$ coefficients suggest the given nutrient source controls more of the variability in pathway specific nutrient loads, which helps to indicate which sources are likely more impactful.

Specific conclusions that can be drawn from these relationships are: (1) high slopes and $\mathrm{r}^{2}$ values in plots with OSDS loading on the y-axis suggests OSDS is a primary control on baseflow and SGD DIN loads, (2) low slopes in agricultural source plots suggests this is the least important anthropogenic source, (3) large DIN loads in SGD suggest groundwater is an important nutrient delivery pathway and deserving of additional management attention, (4) lower $r^{2}$ coefficients in regressions including surface runoff suggest runoff stage nutrient fluxes are not as well predicted by the model as baseflow stage fluxes, which is reasonable because of typically larger variability in surface runoff nutrient concentrations, and (5) high $\mathrm{r}^{2}(0.74)$ and a slope close to unity (1.01) for the total modeled vs. total observed loading plot indicates that the model calibration 
performed as expected and did not systematically bias the model towards over- or underprediction.

Fig 9 Scatterplot matrices of all observed and modeled DIN loading rates. All values are in $\mathrm{kg}$ DIN/day. Abbreviation key: Obs. $=$ Observed loading rates, Comp. $=$ Computed loading rates, OSDS $=$ on-site disposal systems, $\mathrm{AG}=$ Agriculture, $\mathrm{NAT}=$ Natural, $\mathrm{BF}=$ Baseflow, $\mathrm{RO}=$ Surface runoff

\section{Impact Prioritization Ranking}

While absolute magnitudes of DIN loading (Fig 8) provide the most straightforward comparison between different watersheds, this metric may not be the most useful for management purposes. Absolute DIN loads are fundamentally biased towards watershed size, as larger watersheds contain larger numbers of individual sources and thus produce more DIN. To control for this 'area bias', DIN loads can be scaled by watershed area or coastline length (Figs 6 and 7). While area scaled loads essentially show the density of sources, which are more representative of human effects within terrestrial areas, area scaling still does not provide representation of how source waters are affected by dilution upon discharge to coastal waters. One way to more accurately predict terrestrial-hydrologic impacts on coastal waters is to scale absolute DIN loads by the coastline length of each watershed. However, this method does not capture the effects of oceanographic circulation and biological activity, which were beyond the scope of this modeling effort to consider. Also, coastline length scaling is biased by the selection of watershed boundaries, whereas watersheds fronted by more convex parts of the island coastline will have longer coastlines, and watersheds fronted by more concave coastlines will have much shorter coastlines, in some cases significantly increasing the length-scaled DIN release rates. 
In reality, each of these three metrics provides a different and unique presentation of impacts, while at the same time being limited by different biases. Thus, to simplify model results and aid coastal managers, we developed a single watershed prioritization scheme. This scheme incorporates each of the three aforementioned loading metrics, and weights them equally in the output. The raking scheme was developed by calculating the island-wide means of all absolute loads, area scaled loads, and coastline length scaled loads, and computing anomalies from the mean for the three metrics in each watershed. Anomalies were ranked from 1 to 93 with the highest absolute anomaly (i.e. highest DIN impact) from each metric getting assigned the lowest rank. These three ranks were then summed, and the sums ranked from 1 to 93 to incorporate the importance of each metric into a single prioritization ranking score; again with the lowest scoring watersheds being the ones with the highest degree of impact. Results of the prioritization ranking system are shown in Fig 10. This system indicated that Tutuila's most heavily DIN-impacted areas are on the Tafuna-Leone Plain, with the villages of Utulei, Aua, Vaipito (Pago Pago), Aasu, and Tula also being more heavily impacted than other watersheds throughout the island.

Fig 10 Relative impact prioritization through equal-weight ranking of absolute, area-scaled, and coastline length-scaled DIN fluxes from each watershed to the nearshore. Both colors and numeric labels in watersheds indicate the DIN impact prioritization ranking in each watershed with 1 being the most impacted and 93 the least. Note that if two watersheds had the same final score they were assigned the same rank number; thus some numbers are repeated

\section{Discussion}

The cumulative impacts of sediments, nutrients, acidification, and toxic compounds all conspire to drive coastal ecosystem health. However, direct assessment of many of these factors is difficult at best. Because of their low cost and relative simplicity to measure, nutrient concentrations and loads are commonly examined to serve as indicators of human impact. In 
particular, DIN loading has been found to be one of the most robust metrics for understanding coastal ecosystem impacts and thus remains a major consideration for coastal resource management (Caraco and Cole 1999; Waterhouse et al. 2017; Comeros-Raynal et al. 2019).

\section{Identification of Tutuila DIN Hotspots}

Our modeled absolute DIN loading rates for individual watersheds closely tracked watershed size, as larger watersheds typically have higher populations and a larger number of individual sources. For example, the large watersheds of the Tafuna-Leone Plain were ranked as experiencing the highest impacts even after scaling by watershed area or by watershed coastline length. The greater proportion of flat, developable land leading to higher population densities in these areas likely drives the high DIN loading rates from these watersheds. Watersheds with high human population densities such as Tafuna-Leone and Pago Harbor have also been previously reported to be human-impact hotspots on Tutuila (Whitall and Holst 2015; Polidoro et al. 2017; Shuler et al. 2017; Shuler et al. 2019). As such, a higher proportion of the island's resource management attention is focused on the Pala Lagoon and Pago Harbor watersheds. Our model predicted Eastern Tutuila, near Tula Village and the Seetaga area of Western Tutuila to be DIN loading hotspots as well. However, there is currently minimal management or research attention focused on these areas. These villages may be subject to DIN loading impacts that are higher than expected in comparison to adjacent watersheds, thus additional land-use or nutrient source management attention in these areas may be warranted in the future. This exemplifies how the simplicity of applying a single prioritization ranking score can help managers to quickly and easily identify hotspots while integrating a large and diverse array of information into their decision making. 


\section{Implications for Water Quality Monitoring}

On Tutuila, and indeed globally, comparatively little management attention has been given to understanding the effects of groundwater discharge on coastal zones (Carlson et al. 2019). The American Samoa EPA has been progressive in implementing environmental water quality standards for coastal waters and for territorial surface waters. However, this study and others (Whitall and Holst 2015; Shuler et al. 2019) show that groundwater (SGD) is a significant nutrient transport mechanism to Tutuila's coastal areas. This suggests that groundwater quality monitoring and its inclusion in regulatory standards could improve the effectiveness of land use management on Tutuila or other islands with similar hydrogeology. Coastal spring data and SGD loading rates compiled in this work are a useful start for developing a coastal groundwater quality baseline, as this work presents some of the first known, and the most comprehensive set of coastal spring water quality measurements for the territory. Baseline water quality information is not only helpful for detecting acute changes in water quality but is also important in effectively understanding and setting standards for managing land use in a way that protects reef health. Nonetheless, as of this writing, it is rare for U.S. states to define environmental groundwater quality standards, and those that do are typically focused on maintaining drinking water quality (Kimsey 2005; N.J.A.C. 2018). However, American Samoa is relatively small and has a significant motivation to protect reef health, which could make the territory an ideal pilot location to experiment with developing a coastal groundwater monitoring and water quality program.

Another consideration in the design of water quality sampling protocols is the poorly studied, but clearly important mechanism of coastal groundwater discharge occurring within the boundaries of stream mouths and in estuaries. In Fagaalu Stream, which drains to Pago Harbor, Shuler 
(2019) found that surface water nutrient concentrations in the nearshore portions of streams, were significantly elevated relative to concentrations in upper stream reaches. This was attributed to discharging baseflow originating from the nearshore basal-lens aquifer, which, like many other nearshore aquifers on Tutuila, is subject to contamination from cesspools and piggeries that are co-located with human development. We considered this phenomenon when selecting sample data for this and the precursor to this study (Comeros-Raynal et al. 2019), and although it would be most informative to sample streams in multiple locations including both stream mouths and in higher reaches, budget limitations often preclude such efforts. Where limitations exist, the sampling methodology of always sampling near the stream mouth during low tide, can be recommended to ensure that measurements remain comparable between different streams.

\section{Prioritization of Land Use Impacts through Different Hydrologic Pathways}

The DIN loading model developed here enables the assessment of the relative contribution of different land-use sources. We show that OSDS loading is on the order of two to four times higher than DIN loading from other sources, as has been seen in other similar localities/locales (Bishop et al. 2017; Richardson et al. 2017). This result is supported by the trend in water quality management in the territory. Over the last decade in American Samoa, management of pig waste originating from widespread traditional piggeries became a top priority for water resources managers. Coordinated scientific, educational, and regulatory efforts have since significantly reduced the number of pigs and modified pig waste management practices in American Samoa over the last decade (AS-EPA 2005; AS-EPA 2014). Because pigs are no longer the management priority they once were, it has become clear that other land use activities, such as wastewater 
discharge from cesspools, also require management attention. Shuler et al. (2017) found a similar result, suggesting that on the Tafuna-Leone Plain OSDS units account for $300 \%$ more total N loading to groundwater than N sourced from pigs. Results of this study and Shuler et al. (2017) both indicate $\mathrm{N}$-loads from agriculture were relatively insignificant, suggesting OSDS units are currently the highest priority anthropogenic nutrient source for coastal resource manager's attention.

The effects of each DIN source on each hydrologic pathway can also be considered separately. On a conceptual level, piggeries should disproportionately affect surface water quality, and likely have a stronger effect on surface runoff quality, since pig waste is disposed directly on the land surface (Menzi et al. 2010; Shuler et al. 2017). On the other hand, the water quality threats posed by cesspools and septic tanks are more underreported and unknown because OSDS effluent does not directly affect surface water quality. Instead it impacts the groundwater, which then discharges to streams or to the ocean as SGD. Nonetheless, linear regressions between loading from different sources and loading in different hydrologic pathways in Fig 9 suggests that all of Tutuila's anthropogenic DIN sources may control a portion of the variability in all hydrologic pathways. However, this result is confounded by significant collinearity between the three anthropogenic land use sources. Thus, we are not currently able to discount any of the sampled hydrologic pathways from being important coastal DIN transport mechanisms.

\section{Assumptions and Limitations of the DIN Loading Model}

Surface water nutrient concentrations and thus DIN loads are likely to be as variable as surface water discharge itself. However, the high costs, time and effort required to sample at an 
appropriate resolution for characterizing this variability are prohibitive. Therefore, natural variability of stream flows and DIN concentrations were statistically characterized by averaging often low numbers of samples, with wide uncertainty bounds in our results. It should be kept in mind that although this work is useful for assessing the relative differences between watersheds and for showing 'hotspots' where additional management actions may be warranted, there are nonetheless high uncertainties on absolute modeled DIN loads, likely on the order of $55 \%$ to $74 \%$. The relatively low number of surface runoff samples compared to baseflow stage samples collected for this work is another limitation. This likely reduces the accuracy of the model's representation of runoff stage DIN fluxes. Unfortunately, runoff stage data is more difficult to collect than baseflow stage data because runoff conditions occur less-frequently than baseflow conditions, and also because fieldwork conditions are usually less pleasant during runoff conditions, thereby adding human bias to sampling schedules. Additionally, nutrient concentrations in runoff are subject to hysteretic patterns where peak nutrient concentrations may lag behind or precede the runoff peak (depending on nutrient species), making stream stageconcentration relationships significantly more complicated (e.g. Evans and Davies 1998; Kumar 2011). These issues might be alleviated through additional collection of runoff stage data.

Other specific assumptions and limitations of the loading model included: (1) Our partitioning of baseflow and SGD in gauged watersheds relied on the assumption that all net infiltration was either extracted by wells or lost as baseflow or SGD, and neglected any potential for flow between watersheds. (2) For separation of baseflow samples and surface runoff samples, we relied on a stage-based indicator of streamflow. While this was the best available information, stage is clearly not equivalent to discharge. For future work, collecting direct measurements of 
discharge would be far more reliable for this task. (3) Extrapolation of SGD:net-infiltration ratios from gauged to ungauged watersheds relied on the assumption that these ratios were similar for all watersheds. Again, collection of additional discharge measurements would allow for a more spatially distributed assessment of this parameter. (4) We assumed the three modeled anthropogenic DIN sources, OSDS, pigs, and agriculture are the island's only significant anthropogenic sources of N. It was assumed that all other natural sources release DIN evenly throughout the landscape. (5) While DIN source locations were reasonably well known, loading rates, and actual fractions of released DIN escaping attenuation processes such as sorption, volatilization, denitrification, and uptake were represented by a single lumped parameter for each DIN release rate. Though this method appeared empirically robust, it should be remembered that the processes represented by this simplified approach are complex, non-linear, interdependent, and spatially distributed.

Despite the model's limitations, the loading model achieved a reasonable linear-regression fit to available data, with an $\mathrm{r}^{2}$ of 0.74 and a standard error of $1.08 \mathrm{~kg}$-DIN/day when compared with modeled DIN loads. While each loading rate interpretation is subject to different biases, integrating them all into a single prioritization ranking scheme helped to smooth out these biases and also provided land-use managers with a single easy-to understand metric to identify DIN loading 'hotspots' (Fig 10).

\section{Model Archiving and Data Storage}

Recent advancements in cloud-computing technologies, particularly in open-source sharing of online projects, significantly increases methodological transparency and reproducibility of models. We provided dynamic open-source access to this project for managers, researchers, 
regulators, and others by developing the project with GitHub, which manages versioning and retains all necessary raw data files, model code, descriptive information, and output files in a public repository (Shuler and Comeros-Raynal, 2019). We also archived the most recent version of the model for long-term storage in an open-access digital artifact repository (http://doi.org/10.5281/zenodo.3462869). Note that sensitive information or datasets not intended to be publically available, are not posted in raw forms. The model code is licensed under the GNU General Public License v3.0 which is an open-access license designed to explicitly affirm any user's unlimited permission to run, copy, and use the unmodified code from this repository. By designing the model as an interactive live-code document (Jupyter Notebook) it can be modified to potentially address new management questions that come up as we continue to work closely with stakeholders and managers towards the betterment of American Samoa's terrestrial and marine environments. Most importantly, we hope applying this open-source paradigm will provide a blueprint for others to improve upon and translate this method to other locations throughout Oceania.

\section{Conclusions}

We developed a method for integrating geospatial and geochemical information into a modeling framework for predicting island-wide DIN loading to address the critical management need for a better understanding of nutrient impacts to coastal ecosystems. We applied the model to the island of Tutuila, in the Territory of American Samoa, where historical and contemporary streamflow data, water discharge rates from an open-source water budget model, and water quality data from monthly sampling efforts were available. This approach allowed individual identification of the DIN contributions from each hydrologic pathway such as baseflow, surface 
runoff, and SGD. Additionally, the model allowed for the separation of impacts from different land-use sources including OSDS units, pigs, agriculture, and natural background DIN loading. Although the model output provided multiple layers of information, we also synthesized the results into a single prioritization score for each of the island's ninety-three watersheds to assist land managers in prioritizing management actions in DIN loading "hotspots".

To support the continued use and development of this model on Tutuila or other similar islands, and to support accessibility for managers and stakeholders, we have archived model input, model code, and model output data in an open-source, publically-available repository. This work directly supports existing local monitoring and assessment projects implemented to increase understanding of the different stressors to island ecosystems and to improve watershed and island-scale adaptive capacity by integrating a diverse array of biological and physical datasets into a decision making framework. The development of an island-wide nutrient loading model and data tools to support management may be scaled up to the level of regional or geographic reef systems, an issue of critical importance in management regimes and in predicting the response of these reef systems to future changes.

\section{Acknowledgements}

We would like to express our appreciation for the many individuals and agencies who made this work possible by generously providing their time, expertise, and assistance with data collection and field support. These people and agencies include: The American Samoa Department of Marine and Wildlife Coral Reef Advisory Group Staff, specifically Alice Lawrence, Motusaga Vaeoso, and Kim McGuire. The National Marine Sanctuary of American Samoa, especially Dr. 
Mareike Sudek. The American Samoa Environmental Protection Agency, specifically, Fa'amao

Asalele, Jr., Christianera Tuitele, Jewel Tuiasosopo and Josephine Regis and University of Guam

- Dr. Peter Houk. Funding for this work was provided by the United States Environmental

Protection Agency Region IX Wetland Program Development Grant, through the American Samoa Environmental Protection Agency.

\section{Author Contributions:}

All authors contributed to the study conception and design. Model development was performed by Christopher Shuler. The first draft of the manuscript was written by Christopher Shuler and Mia Comeros-Raynal contributed considerably to the betterment of subsequent drafts, with significant additions to the text. All authors read and approved the final manuscript. 


\section{References}

AS-DOC - American Samoa Department of Commerce. (2002) Tutuila Minor Watersheds. [Data file]. http://portal.gis.doc.as (accessed June 2014)

AS-DOC - American Samoa Department of Commerce. (2009) Buildings layer for Tutuila Island. [Data file]. http://portal.gis.doc.as (accessed June 2014)

AS-DOC - Amercan Samoa Department of Commerce. (2013) The 2013 Statistical Yearbook for American Samoa. Pago Pago, AS: Amercan Samoa Department of Commerce.

http://doc.as.gov/wp-content/uploads/2011/06/2013-Statistical-Yearbook-Final-Draft.pdf.

AS-EPA - American Samoa Environmental Protection Agency (2005) American Samoa watershed management and protection program annual report. AS EPA report. Pago Pago, American Samoa

AS-EPA - American Samoa Environmental Protection Agency. (2013) American Samoa Water Quality Standards: 2013 Revision. Administrative Rule No. 001-2013. Available online: https://www.epa.gov/sites/production/files/2014-12/documents/aswqs.pdf (accessed January 2019).

AS-EPA - American Samoa Environmental Protection Agency (2014) American Samoa watershed management and protection program annual report. AS EPA report, Pago Pago, American Samoa

ASPA - American Samoa Power Authority. (2017) Groundwater Extraction Rates Spreadsheet. [Dataset]. 1st Road Airport, Pago Pago, AS 96799

Bentley, C.B. (1975). Ground-water resources of American Samoa with emphasis on the TafunaLeone Plain, Tutuila Island. US Geological Survey Report No. 75-29.

Bishop, J. M., Glenn, C. R., Amato, D. W., \& Dulai, H. (2017) Effect of land use and groundwater flow path on submarine groundwater discharge nutrient flux. Journal of Hydrology: Regional Studies, 11, 194-218. https://doi.org/10.1016/j.ejrh.2015.10.008

Caraco, N. F., \& Cole, J. J. (1999) Human impact on nitrate export: an analysis using major world rivers. Ambio, 28(2), 167-170.

Carlson, R. R., Foo, S. A., \& Asner, G. P. (2019) Land use impacts on coral reef health: a ridgeto-reef perspective. Frontiers in Marine Science, 6, 562. 
Comeros-Raynal, M. T., Lawrence, A., Sudek, M., Vaeoso, M., McGuire, K., Regis, J., \& Houk, P. (2019) Applying a ridge-to-reef framework to support watershed, water quality, and community-based fisheries management in American Samoa. Coral Reefs, 1-16. https://doi.org/10.1007/s00338-019-01806-8

Daly, C., J. Smith, M. Doggett, M. Halbleib, and W. Gibson. (2006) High-resolution climate maps for the Pacific basin islands, 1971-2000. Final Report. National Park Service, Pacific West Regional Office.

Delevaux, J. M., Whittier, R., Stamoulis, K. A., Bremer, L. L., Jupiter, S., Friedlander, A. M., ... \& Toonen, R. (2018) A linked land-sea modeling framework to inform ridge-to-reef management in high oceanic islands. $c$ 13(3), e0193230.

https://doi.org/10.1371/journal.pone.0193230

D’elia, C.F.; Webb, K.L.; Porter, J.W. (1981) Nitrate-rich groundwater inputs to Discovery Bay, Jamaica: A significant source of N to local coral reefs? Bull. Mar. Sci., 31, 903-910.

Evans, C., \& Davies, T. D. (1998) Causes of concentration/discharge hysteresis and its potential as a tool for analysis of episode hydrochemistry. Water Resources Research, 34(1), 129-137. https://doi.org/10.1029/97WR01881

Hawai'i Administrative Rules (2013) Amendment and Compilation of Chapter 11-54. State of Hawai'i Department of Health. Honolulu, HI

Hughes TP et al. (2007a) Phase Shifts, Herbivory, and the Resilience of Coral Reefs to Climate Change. Current Biology 17:360-365 doi:https://doi.org/10.1016/j.cub.2006.12.049

Hughes TP, Bellwood DR, Folke CS, McCook LJ, Pandolfi JM (2007b) No-take areas, herbivory and coral reef resilience. Trends Ecol Evol 22:1-3 doi:10.1016/j.tree.2006.10.009

Izuka, S.K., J.A. Perreault, and T.K. Presley. (2007) Areas contributing recharge to wells in the Tafuna-Leone Plain, Tutuila, American Samoa. Honolulu, HI: Geological Survey (US). Report no. 2007-5167. https://pubs.er.usgs.gov/publication/sir20075167.

Kimsey, M. B. (2005) Implementation guidance for the ground water quality standards. Washington State Department of Ecology Publication, (96-02). https://fortress.wa.gov/ecy/publications/documents/9602.pdf (accessed 2019-06-20) 
Kluyver, T., Ragan-Kelley, B., Pérez, F., Granger, B. E., Bussonnier, M., Frederic, J., ... \& Ivanov, P. (2016, May) Jupyter Notebooks-a publishing format for reproducible computational workflows. In ELPUB (pp. 87-90).

Kumar V. (2011) Hysteresis. In: Singh V.P., Singh P., Haritashya U.K. (eds) Encyclopedia of Snow, Ice and Glaciers. Encyclopedia of Earth Sciences Series. Springer, Dordrecht. https://doi.org/10.1007/978-90-481-2642-2_252

Littler MM, Littler DS, Brooks BL (2006) Harmful algae on tropical coral reefs: Bottom-up eutrophication and top-down herbivory. Harmful Algae 5:565-585 doi:10.1016/j.hal.2005.11.003

McCook, L.J. (1999) Macroalgae, nutrients and phase shifts on coral reefs: Scientific issues and management consequences for the Great Barrier Reef. Coral Reefs, 18, 357-367. https://doi.org/10.1007/s003380050213

Menzi, H., Oenema O., Burton C., Shipin O., Gerber P., Robinson T., Franceschini G. (2010) Impacts of intensive livestock production and manure management on the environment, chap 9. In: Steinfeld H., Mooney H. A., Schneider F., Neville L.E. (eds) Livestock in a changing landscape, vol 1: drivers, consequences, and responses. Island Press, Washington, DC, pp 139163

Meyer, R.A., Seamon, J.O., Fa'aumu, S., and Lalogafuafua, L. (2016) Classification and Mapping of Wildlife Habitats in American Samoa: An object-based approach using high resolution orthoimagery and LIDAR remote sensing data. Report prepared for American Samoa Department of Marine and Wildlife Resources.

Moosdorf, N.; Stieglitz, T.; Waska, H.; Dürr, H.H.; Hartmann, J. (2015) Submarine groundwater discharge from tropical islands: A review. Grundwasser, 20, 53-67.

https://doi.org/10.1007/s00767-014-0275-3

Morton, S.L.; Shuler, A.; Paternoster, J.; Fanolua, S.; Vargo, D. (2011) Coastal eutrophication, land use changes and Ceratium furca (Dinophyceae) blooms in Pago Pago Harbor, American Samoa 2007-2009. Chin. J. Oceanol. Limnol., 29, 790-794. https://doi.org/10.1007/s00343011-0507-7

Nelder, J. A., \& Mead, R. (1965) A simplex method for function minimization. The computer journal, 7(4), 308-313. https://doi.org/10.1093/comjnl/7.4.308

N.J.A.C. - New Jersey Administrative Code. (2018) Ground Water Quality Standards 
https://www.nj.gov/dep/rules/rules/njac7_9c.pdf (accessed 2019-06-20)

https://doi.org/10.1002/dap.30613

Pendleton, L.H. (1995) Valuing coral reef protection. Ocean Coast. Manag., 26, 119-131. https://doi.org/10.1016/0964-5691(95)00007-O

Perreault, J.A. (2010) Development of a water budget in a tropical setting accounting for mountain front recharge. Masters Thesis, University of Hawaii at Manoa. Honolulu, HI.

Polidoro, B. A., Comeros-Raynal, M. T., Cahill, T., \& Clement, C. (2017) Land-based sources of marine pollution: Pesticides, PAHs and phthalates in coastal stream water, and heavy metals in coastal stream sediments in American Samoa. Marine pollution bulletin, 116(1-2), 501-507. https://doi.org/10.1016/j.marpolbul.2016.12.058

Richardson, C. M., Dulai, H., \& Whittier, R. B. (2017) Sources and spatial variability of groundwater-delivered nutrients in Maunalua Bay, O‘ahu, Hawai'i. Journal of Hydrology: Regional Studies, 11, 178-193.

Shuler, C. K., El-Kadi, A. I., Dulai, H., Glenn, C. R., \& Fackrell, J. (2017) Source partitioning of anthropogenic groundwater nitrogen in a mixed-use landscape, Tutuila, American Samoa. Hydrogeology Journal, 25(8), 2419-2434. https://doi.org/10.1007/s10040-017-1617-x

Shuler and El-Kadi, (2018a) Groundwater Recharge for Tutuila, American Samoa Under Current and Projected Climate as Estimated with SWB2, a Soil Water Balance Model. WRRC Project Completion Report, Water Resources Research Center University of Hawai'i at Manoa, Honolulu, Hawai'i 96822

Shuler, C. K., Amato, D. W., Veronica Gibson, V., Baker, L., Olguin, A. N., Dulai, H., ... \& Alegado, R. A. (2019) Assessment of Terrigenous Nutrient Loading to Coastal Ecosystems along a Human Land-Use Gradient, Tutuila, American Samoa. Hydrology, 6(1), 18.

https://doi.org/10.3390/hydrology6010018

Shuler, C. K., \& Mariner M.K.E (2019). cshuler/ASPA-UH_Integrated_Modeling_Framework. V1.0.2, Zenodo, doi: http://doi.org/10.5281/zenodo.3460214

Shuler, C. K., \& Comeros-Raynal, M. (2019). cshuler/R2R_DIN_Loading_Model: Provisional release for DOI generation 2 (Version v1.0). Zenodo. http://doi.org/10.5281/zenodo.3462869 
Shuler C. K. (2019) From Recharge to Reef: Assessing The Sources, Quantity, and Transport of Groundwater on Tutuila Island, American Samoa. (Doctoral dissertation, University of Hawaii Manoa, Honolulu, HI)

Shuler, C.K., \& El-Kadi, A.I. (2019, October 1). cshuler/SWB2-Tutuila_fork: SWB2 Water Budget Model for Tutuila: version for DOI generation (Version V1.2). Zenodo. http://doi.org/10.5281/zenodo.3466114

Smith, S.V.; Kimmerer, W.J.; Laws, E.A.; Brock, R.E.; Walsh, T.W. (1981) Kaneohe Bay sewage diversion experiment: Perspectives on ecosystem responses to nutritional perturbation. Pac. Sci., 35, 279-395.

SWRCB - State Water Resources Control Board. (2015) 2015 California Ocean Plan Water Quality Control Plan Ocean Waters of California. State of California State Water Resources Control Board. Sacramento, Ca. Available online:

https://www.epa.gov/sites/production/files/2017-01/documents/ca-cop2012.pdf (accessed on May 2019).

Thornthwaite, C.W., and J.R. Mather. (1955) The water balance. Publications in Climatology (Laboratory of Climatology) 8(1): 1-86.

Wahl, K.L., Wahl, T.L., (1995) Determining the flow of comal springs at New Braunfels, Texas, in Proceedings of Texas Water'95, August 16-17, 1995, San Antonio, Texas: American Society of Civil Engineers, pp. 77-86.

Waterhouse, J., Schaffelke, B., Bartley, R., Eberhard, R., Brodie, J., Star, M., ... \& Kroon, F. (2017) 2017 Scientific Consensus Statement: Land Use Impacts on Great Barrier Reef Water Quality and Ecosystem Condition. Department of the Environment and Energy.

Westenbroek, S. M., Engott, J. A., Kelson, V. A., \& Hunt, R. J. (2018) SWB Version 2.0-A Soil-Water-Balance Code for Estimating Net Infiltration and Other Water-Budget Components (No. 6-A59). US Geological Survey. https://doi.org/10.3133/tm6A59

Whitall, D., and S. Holst. (2015) Pollution in Surface Sediments in Faga'alu Bay, Tutuila, American Samoa. NOAA Technical Memorandum NOS NCCOS 201. Silver Spring, MD. 54 pp. https://doi.org/10.7289/V5/TM-NOS-NCCOS-201

Wong, M.F. (1996) Analysis of streamflow characteristics for streams on the island of Tutuila, American Samoa. US Geological Survey Water Resources Investigations Report No. 95-4185, Honolulu, HI. 


\section{Figure icons and captions for reviewer convenience (not for publication) full size figures below}
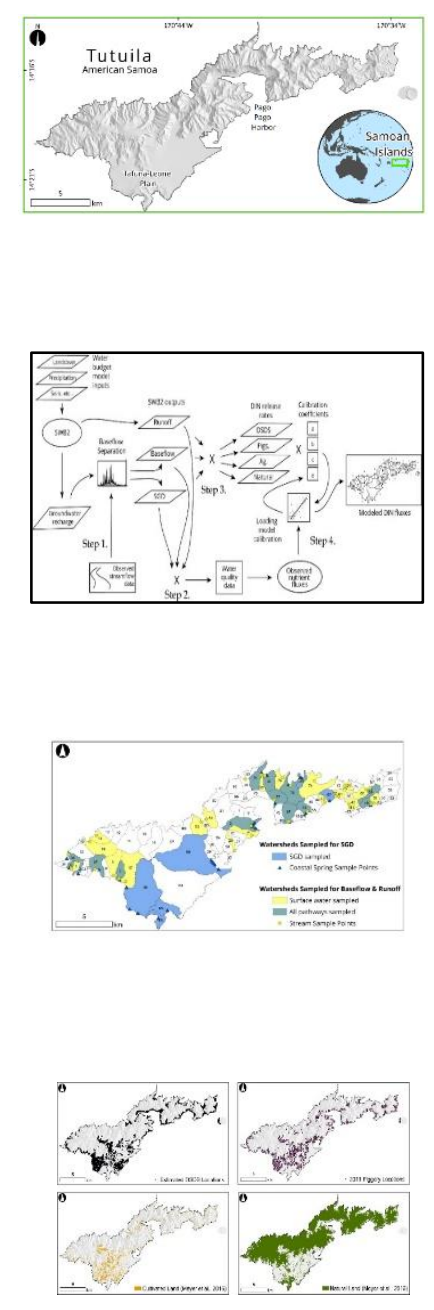

Fig 3 Locations of stream and coastal spring sample sites shown as circles and triangles, respectively, with shaded model watersheds draining to each site. Model designated watershed ID numbers are also shown for reference

Fig 4 Locations of DIN sources used as model input. Initial DIN release rates from Shuler et al. (2017) were $0.021 \mathrm{~kg}$-DIN/day per OSDS unit, $0.0381 \mathrm{~kg}$ DIN/day per pig, $0.77 \mathrm{~kg}$-DIN/day per $\mathrm{km} 2$ of agricultural land, and $0.36 \mathrm{~kg}$ DIN/day per $\mathrm{km} 2$ of natural land

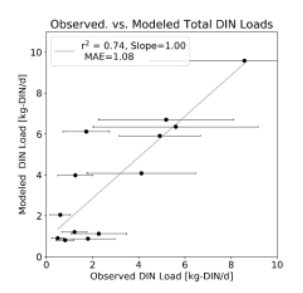

Fig 5 Scatterplot of final calibrated observed vs. modeled total DIN loads, with error bars representing propagated error on observed loads. Although the nonlinearity of model optimization precluded standard error propagation through the model, the mean average error (MAE) associated with model calibration was 1.08 $\mathrm{kg}$-DIN/d. Grey line is the 1:1 line and represents a fixed model slope of 1 

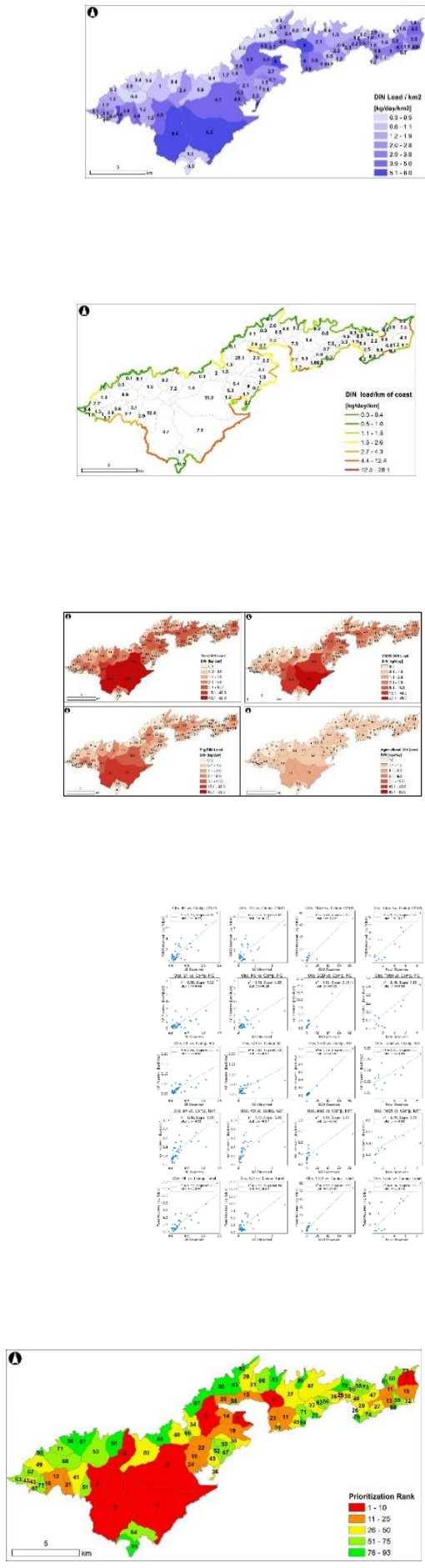

Fig 6 Relative model calculated DIN loading rates for each watershed scaled by sub watershed area, in $\mathrm{kg}$-DIN/day per $\mathrm{km}^{2}$ of land and Numbers within watersheds show each of the DIN loads in $\mathrm{kg} / \mathrm{day} / \mathrm{km}^{2}$

Fig 7 Relative model calculated DIN loading rates for each watershed, scaled by length of watershed shoreline in $\mathrm{kg}$-DIN/day per $\mathrm{km}$ of coastline. Numbers within watersheds show each of the DIN loads in $\mathrm{kg} / \mathrm{day} / \mathrm{km}$

Fig 8 Comparisons between modeled DIN loading rates as separated by each nutrient source. Upper left panel shows total modeled DIN loads from all sources, and the other three panels (clockwise from upper right) show the absolute magnitude of DIN loaded to each watershed from OSDS units, pigs, and agriculture, respectively

Fig 9 Scatterplot matrices of all observed and modeled DIN loading rates. All values are in kg-DIN/day. Abbreviation key: Obs. = Observed loading rates, Comp. $=$ Computed loading rates, OSDS $=$ on-site disposal systems, $\mathrm{AG}=$ Agriculture, $\mathrm{NAT}=$ Natural, $\mathrm{BF}=$ Baseflow, $\mathrm{RO}=$ Surface runoff

Fig 10 Relative impact prioritization through equal-weight ranking of absolute, area-scaled, and coastline length-scaled DIN fluxes from each watershed to the nearshore. Both colors and numeric labels in watersheds indicate the DIN impact prioritization ranking in each watershed with 1 being the most impacted and 93 the least. Note that if two watersheds had the same final score they were assigned the same rank number; thus some numbers are repeated 